\title{
From resilience to vulnerability: mechanistic insights into the effects of stress on transitions in critical period plasticity
}

\section{Bridget L. Callaghan*, Bronwyn M. Graham, Stella Li and Rick Richardson}

School of Psychology, The University of New South Wales, Sydney, NSW, Australia

\section{Edited by:}

Tania L. Roth, University of Delaware USA

\section{Reviewed by:}

Opal Ousley, Emory University, USA Tania L. Roth, University of Delaware, USA

\section{*Correspondence:}

Bridget L. Callaghan, School of Psychology, The University of New South Wales, Mathews Building, High Street, Kensington, Sydney, NSW 2052, Australia

e-mail: b.callaghan@unsw.edu.au

While early experiences are proposed to be important for the emergence of anxiety and other mental health problems, there is little empirical research examining the impact of such experiences on the development of emotional learning. Of the research that has been performed in this area, however, a complex picture has emerged in which the maturation of emotion circuits is influenced by the early experiences of the animal. For example, under typical laboratory rearing conditions infant rats rapidly forget learned fear associations (infantile amnesia) and express a form of extinction learning which is relapse-resistant (i.e., extinction in infant rats may be due to fear erasure). In contrast, adult rats exhibit very long-lasting memories of past learned fear associations, and express a form of extinction learning that is relapse-prone (i.e., the fear returns in a number of situations). However, when rats are reared under stressful conditions then they exhibit adult-like fear retention and extinction behaviors at an earlier stage of development (i.e., good retention of learned fear and relapse-prone extinction learning). In other words, under typical rearing conditions infant rats appear to be protected from exhibiting anxiety whereas after adverse rearing fear learning appears to make those infants more vulnerable to the later development of anxiety. While the effects of different experiences on infant rats' fear retention and extinction are becoming better documented, the mechanisms which mediate the early transition seen following stress remain unclear. Here we suggest that rearing stress may lead to an early maturation of the molecular and cellular signals shown to be involved in the closure of critical period plasticity in sensory modalities (e.g., maturation of GABAergic neurons, development of perineuronal nets), and speculate that these signals could be manipulated in adulthood to reopen infant forms of emotional learning (i.e., those that favor resilience).

Keywords: maternal-separation, FGF2, fear conditioning, memory retention, extinction, development, infant, critical period

\section{INTRODUCTION}

Early life experiences have long been considered critical for the establishment of mental health. Exposure to a range of childhood adversities such as maladaptive family functioning, rearing in an institutional setting, and trauma lead to increased mental health risk and difficulties in emotional regulation and cognitive functioning (1-5). In both humans and non-human species the early rearing environment has been shown to influence the development of brain regions critical to emotional processing and/or mental health outcomes $(3,6-8)$. Despite the recognized importance of early life experiences in the establishment of mental health however, there has been surprisingly little empirical research which examines the role of early experiences (such as adverse rearing) on the development of emotional learning. Yet some forms of emotional learning (e.g., learning to fear and learning to inhibit fear responses) are critically involved in both the establishment and treatment of mental health disorders in humans [see (9), for a review (10-12)]. Further, evidence from animal models has demonstrated considerable developmental heterogeneity in the processes involved in fear learning and fear inhibition (13-18). Hence, understanding the maturation of emotional learning and how its developmental trajectory is altered by different early experiences might aide in our understanding and treatment of mental health disorders across the lifespan.

In this review we describe the normal trajectory of fear learning across the infancy to juvenile periods of development in the rodent and discuss how developmental dissociations in these learning processes are altered by a variety of early life experiences (specifically, exposure to early life adversity or fibroblast growth factor-2; FGF2). Considering the high degree of similarity in fear learning outcomes following early manipulation of the rearing environment and FGF2, we propose a model via which the experience of early adversity might activate, within the limbic circuit, molecular signals known to be involved in critical periods of plasticity in other brain regions via an FGF2-dependent pathway. The review ends with a discussion on how the proposed model might guide further pre-clinical research in this field as well as highlighting potential areas for translation to humans. 


\section{DEVELOPMENTAL DIFFERENCES IN FEAR LEARNING}

In recent years, studies using Pavlovian fear conditioning have demonstrated a number of fundamental differences in emotional learning in infant and adult animals. During a typical Pavlovian fear conditioning procedure an initially neutral conditioned stimulus (CS; e.g., noise) is paired with an aversive unconditioned stimulus (US; e.g., footshock). Such pairings rapidly lead the animal to express a species-specific defensive/fear response toward the CS [e.g., freezing in the rat; (19)]. Although both infant and adult rodents can learn a CS-US association during fear conditioning, their retention of those fear memories differs dramatically. Specifically, following fear conditioning adult rats will typically express fear to that cue for the rest of their life (20). Infant rats, on the other hand, exhibit rapid forgetting, a phenomenon known as infantile amnesia (13). For example, when given two pairings of a white noise CS with a foot shock US, both infant [i.e., postnatal day (P) 16] rats and juvenile (i.e., P23) rats show equivalent levels of fear immediately after training (18). However, when tested 2 days after training, infants show a dramatic decrease in fear, while juveniles continue to express a high level of fear in the presence of the CS. This suggests that while infant animals can acquire fear just as readily as older animals, they do not retain the memory across an extended period of time $(13,21,22)$. This profound and spontaneous forgetting is not limited to infant rats but is experienced by all altricial animals, including humans (23). For example, humans are generally unable to recall events that occurred prior to the age of 3 years and have hazy memories of events that occurred until around 5-6 years of age (24).

One question of interest to neuroscience researchers is what happens to the memory trace following infantile amnesia. That is, does the forgetting represent decay in the memory trace, leading to eventual erasure of that memory, or are infant memories simply unable to be retrieved? The evidence suggests that infantile forgetting often represents a retrieval failure. Numerous studies have shown that a pre-test reminder treatment effectively reverses the deficit in retention, suggesting that infantile amnesia is caused by a failure of cues to spontaneously retrieve the memory trace $(15,25-$ 27). In addition, reducing GABAergic inhibition in the infant rat at test (via systemic injection of FG7142; a partial inverse agonist of the $\mathrm{GABA}_{\mathrm{A}}$ receptor) leads to a forgotten memory being expressed $(15,28)$. Interestingly, studies have shown that administration of midazolam, which increases $\mathrm{GABA}_{\mathrm{A}}$ activity, in adult rats has strong amnestic effects (29), suggesting that infantile forgetting may be an exaggerated form of adult memory loss.

\section{DEVELOPMENTAL DIFFERENCES IN FEAR INHIBITION}

Another area where developmental differences are observed is in the inhibition of fear. That is, once fear is acquired it can then be decreased or inhibited through a process known as extinction. During a typical extinction procedure the animal is repeatedly exposed to the CS without the reinforcing US (e.g., shock). In the last decade, extensive research has been conducted examining the behavioral, neural, and molecular mechanisms underlying fear extinction. On a behavioral level, it is widely accepted that extinction in older animals (e.g., juvenile and adult animals) is not simply erasure of the original fear memory. Instead, extinction is believed to involve the formation of a new inhibitory (CS-noUS) memory. Evidence for the "new inhibitory learning" account of extinction comes from both rodent and human studies showing that fear can return following extinction training through either a change in context [renewal; e.g., $(30,31)]$, presentation of an aversive stimulus [reinstatement; e.g., $(32,33)$ ], or simply the passage of time [spontaneous recovery; e.g., $(33,34)]$. Thus, in older animals, extinction is relapse-prone.

The idea that extinction involves new learning in juvenile and adult animals is further supported by evidence from pharmacological studies demonstrating that extinction involves the same cellular mechanisms as other forms of new learning. For instance, both fear conditioning and fear extinction require activation of the $N$-methyl-D-aspartate receptor (NMDAr), as administration of DL-2-amino-5-phosphonovaleric acid (APV; an NMDAr antagonist) either systemically or directly into the brain disrupts both forms of learning (35-37). Conversely, systemic or intra-amygdala administration of the NMDAr partial agonist D-cycloserine (DCS) enhances extinction retention (38-40). Other cellular mechanisms involved in the mature form of fear extinction have also been explored. For instance, along with NMDAr transmission, fear extinction in juvenile/adult rats has been shown to rely on GABAergic $(41,42)$ and opioidergic transmission $(43,44)$.

The characteristics of extinction in infant rodents have also begun to be explored and the results suggest that infant rodents exhibit a qualitatively different extinction profile compared to juvenile and adults. Whereas adult animals exhibit relapse-prone extinction, infants exhibit relapse-resistant fear extinction. That is, infant P17 animals do not show renewal, reinstatement, or spontaneous recovery following extinction $(16,42,45,46)$. The lack of relapse behavior seen after extinction in the young animal suggests that extinction at this age is mediated by a fundamentally different mechanism, which might be best characterized as erasure of the original fear memory rather than new learning. In support of this possibility, other studies have demonstrated that extinction in infant animals is not dependent on NMDArs (47); in contrast to P24 rats, systemic administration of the NMDAr antagonist MK801 did not impair extinction retention in P17 animals. This effect is not due to a generalized lack of NMDAr-involvement in infant learning because the same drug was shown to impair fear acquisition in rats when given prior to conditioning in infancy. These findings suggest that while NMDArs are involved in some forms of learning during infancy (i.e., fear conditioning), they are not involved in others (i.e., fear extinction).

Other neurotransmitters have also been shown to differentially modulate early extinction memories. For instance, unlike juvenile and adult rats, GABAergic transmission does not affect long-term extinction in infant rats (42), suggesting that extinction does not involve formation of a new "inhibitory" association in young rats. On the other hand, some neurotransmitter systems do appear to be involved in extinction across age. Specifically, endogenous opioids appear to regulate extinction in infant animals, as P17 rats given the opioid receptor antagonist naloxone exhibited impaired within-session extinction compared to animals given saline (44); a finding which is similar to that seen in adult rats (43).

The developmental differences in fear inhibition are not only observed on the behavioral and pharmacological levels as there are also marked differences in the neural circuitry which supports 
extinction across development. In adult animals, lesion, immunohistochemical, and electrophysiological studies have implicated the amygdala, medial prefrontal cortex (mPFC), and hippocampus in the extinction of fear [see (48-50), for extensive reviews on the role of these structures in extinction]. Specifically, a widely accepted neural model of extinction proposes that the amygdala is involved in the acquisition and consolidation of learned fear [e.g., (51)], while the mPFC is important for regulating the expression of fear through either inhibiting or exciting amygdalar neuron output [e.g., (50)]. Additionally, the hippocampus appears to be involved in the contextual modulation of extinction through its projections to the $\operatorname{mPFC}(52,53)$.

While this neural model of extinction has been predominantly based on rodent studies, there is evidence to suggest that a similar circuitry is involved in regulating emotional memories in humans (54). For example, Phelps and colleagues showed that the mPFCamygdala circuit is activated in humans following extinction training (55), while Kalisch et al. (56) found that retrieval of a contextdependent extinction memory activated the hippocampal-mPFC circuit. Interestingly, this "extinction circuit" has been shown to be dysfunctional in individuals with post-traumatic stress disorder (PTSD). Specifically, some studies have found that individuals with PTSD exhibit hypoactivation of the fear inhibition components of the circuit (i.e., mPFC and hippocampus) and hyperactivation of the fear activation components of the circuit (i.e., amygdala), relative to healthy controls [e.g., $(12,57)]$.

While the extinction circuit has been well documented in adult rodents and adult humans, until very recently this circuit had not been examined at earlier stages of development. Over the past 5 years, however, some progress has been made in mapping the neural circuitry mediating extinction in the developing animal. Those studies indicate that if extinction occurs in the juvenile stage of development, then it involves the same neural circuit as extinction in adulthood. In contrast, extinction in the infant stage of development appears to involve a different circuit. For example, Kim and Richardson (58) found that inactivating the amygdala (via infusion of the $\mathrm{GABA}_{\mathrm{A}}$ agonist muscimol) prior to extinction significantly impaired long-term extinction in both P24 and P17 rats. Further, it was observed that there was an increase in the number of phosphorylated mitogen-activated protein kinase (pMAPK) neurons in the basolateral amygdala (BLA) following extinction training in rats of both ages (59). Therefore, it seems that the amygdala is an important structure for the extinction of conditioned fear in rats, regardless of age. In contrast, the mPFC appears to mediate fear extinction only in older animals [i.e., juveniles and adults; (59)]. In that study, infusion of muscimol into the mPFC prior to extinction training impaired extinction retention in $\mathrm{P} 24$ rats but not in $\mathrm{P} 17$ rats. In addition, while extinction training caused an increase in pMAPK-labeled neurons in the MPFC of P24 rats, there was no extinction-related change in pMAPKlabeled neurons in that structure in younger animals. Together, the research on fear extinction in the infant rat appears to suggest that infants recruit a much simpler neural circuit during extinction than do rats extinguished at later stages of development (i.e., juvenile through to adulthood). It has been proposed that these neural differences in extinction might underlie the less flexible extinction behavior seen in infant rats. That is, perhaps the lack
Table 1 | Summary of the behavioral and neural characteristics of the fear retention and extinction systems in adult and infant $(<$ P21) rodents.

\begin{tabular}{lccc}
\hline & $\begin{array}{c}\text { Adult } \\
\text { rodent }\end{array}$ & $\begin{array}{c}\text { Infant } \\
\text { rodent }\end{array}$ & $\begin{array}{c}\text { Infant rodents following } \\
\text { early stress/CORT/FGF2 }\end{array}$ \\
\hline Renewal & $\checkmark$ & $\times$ & $\checkmark$ \\
Reinstatement & $\checkmark$ & $\times$ & $\checkmark$ \\
NMDA & $\checkmark$ & $\times$ & $?$ \\
GABA & $\checkmark$ & $\times$ & $?$ \\
Endogenous opioids & $\checkmark$ & $\checkmark$ & $?$ \\
Amygdala & $\checkmark$ & $\checkmark$ & $?$ \\
mPFC & $\checkmark$ & $\times$ & $\checkmark$ \\
Good fear retention & $\checkmark$ & $\times$ & \\
\hline
\end{tabular}

$\checkmark$ Indicates that the phenomenon is present in age or treatment groups; $\times$ indicates that the phenomenon is absent in age or treatment groups; ? indicates that the phenomenon has not yet been examined in the age or treatment group. See text for definition of the terms used in this table.

of relapse following infant extinction in the rat is the outcome of a simple extinction circuit which cannot integrate multiple, contextually gated associations. See Table 1 for a summary of the behavioral and neural differences in extinction and fear retention across development.

The current literature clearly indicates that fear retention and fear inhibition are dynamic processes that exhibit considerable developmental heterogeneity. Whereas infant rats exhibit marked forgetting and use a simpler extinction system characterized by a resistance to relapse, older rats demonstrate better memory retention and use a more flexible neural circuit that results in relapse-prone extinction learning. While examination of these differences has occurred primarily in animal models, there is evidence that at least one of the transitions (i.e., the transition from infantile amnesia to adult-like memory retention) also occurs in developing humans. It is now commonly accepted that memories formed before the age of approximately 3 years in humans are generally inaccessible to conscious recollection in adulthood [e.g., $(24,60)]$. While much of the human research on infantile amnesia has focused on various cognitive factors that might contribute to the effect [e.g., language acquisition, development of self-concept, increasing ability to utilize reminder cues; (61-63)], the occurrence of the same effect in non-human animals suggests that more basic neurobiological mechanisms might provide a better account for infantile amnesia. In contrast to the complimentary findings on infantile amnesia across rodents and humans, there hasn't been any, to our knowledge, research examining whether the transition from relapse-resistant to relapse-prone extinction is also a feature of human development. Future studies should examine whether the transition in extinction mechanisms also occurs in humans.

The fact that developmental transitions in emotional learning take place in humans as well as rodents is of particular interest, suggesting that findings in either species might be successfully translated to the other. Indeed, a mechanistic understanding of the developmental transitions in emotional learning across species might have considerable clinical implications because anxiety disorders are characterized by persistent expression of fear and 
high rates of treatment relapse. In an effort to uncover some of the mechanisms which regulate the expression of infant fear learning within a rodent model, some very recent studies have begun to examine factors which are involved in the transition from infant- to adult-like fear learning, with a view to manipulating these mechanisms in adulthood to promote infant-like forgetting and relapse-resistant extinction.

\section{EARLY EXPERIENCES REGULATE THE TRANSITION BETWEEN INFANT- AND ADULT-LIKE FEAR LEARNING IN RODENT MODELS}

Two different types of early experience have recently been shown to affect the age at which rats transition between infant- and adultlike fear learning. While these experiences are vastly different in nature, they both appear to impact the developmental transition in fear learning in similar ways (i.e., both manipulations lead to early expression of adult-like fear retention and extinction behaviors).

\section{STRESS}

It has been known for decades that exposure to stressors or stress hormones (corticosterone; CORT) can program the maturation of fear responding. For example, rats begin to exhibit species-specific defense responses (freezing, inhibition of ultrasonic vocalizations; USV) to the presence of a strange adult male/male odor at approximately P10. Further, while the amygdala is not activated by the presentation of a male odor in rats younger than P10, amygdala activation is increased following presentation of the same stimulus in rats aged P10 and older (64-66). Defense responding and amygdala activation can be elicited by presentation of a potential predator odor earlier if rats are given exogenous CORT at P8. Further, these responses can be delayed if rats are adrenalectomized, which leads to a reduction in CORT [i.e., removal of the adrenal gland and subsequent reduction in CORT; (66-69)].

In addition to the stress-induced acceleration of unlearned fear reaction development, the maturation of learned fear reactions also appears to be affected by stress exposure. For example, in the second postnatal week of life rats exhibit a developmental transition in their behavioral and neural response to an odor previously paired with shock. Specifically, in rats aged P10 and older odor-shock conditioning leads to subsequent avoidance of the shock-paired odor and activation of the amygdala. However, rats conditioned at $\mathrm{P} 6-\mathrm{P} 8$ exhibit a paradoxical approach response toward the odor $(70,71)$. In addition, presentation of the shockpaired odor does not lead to increased activity in the amygdala of P8 rats (72), suggesting that different neural structures are involved in the conditioned responses exhibited by $\mathrm{P} 10$ and $\mathrm{P} 8$ rats. Interestingly, if rats were raised in a stressful rearing environment, or were given a CORT injection before test, then a precocious avoidance response to the shock-paired odor was observed at $\mathrm{P} 8$, which was correlated with increased amygdala activity (72-75). Thus, early life stress in rodents accelerates the transition between infant- and adult-like behaviors and neural responses in odor-shock associative learning just like it accelerates the development of unlearned fear responses to a potential predator odor.

Although environmental effects on the maturation of fear responses have been investigated for some time, how the environment affects development of fear retention and fear extinction has only recently begun to be investigated. Interestingly, those studies show that early exposure to stress or CORT also accelerates the maturation of fear retention and extinction learning. Specifically, compared to a group of standard-reared (SR) infant rats, infants exposed to maternal-separation (MS; $180 \mathrm{~min}$ separation from $\mathrm{P} 2$ to $\mathrm{P} 14$ ) before conditioning on P17 express fear memories for longer periods of time (76). While SR infants forgot a conditioned association in as little as 10 days, MS infants expressed memory for the conditioned association up to 30 days after training. Similarly, pups that were suckled by a SR mother that had been exposed to CORT in her drinking water (from P2 to P14), but not pups suckled by vehicle-exposed mothers, also exhibited longer retention of fear memories. Taken together, those results suggest that early stress/CORT exposure leads to an accelerated transition in the fear retention system used by infant rats. In other words, rats make a precocious transition from the infantile amnesia system to the adult-like retention system following exposure to stress/CORT.

It is not only an early transition into adult-like retention that is seen following MS however. In another set of studies the effect of MS on the expression of two relapse phenomena after extinction (fear renewal and reinstatement) was examined in infant rats (77). It was shown that while the SR infant rats did not exhibit either of those relapse phenomena [replicating past findings in P17 rats; $(16,45)]$, the MS infants did. In other words, following MS rats made an early transition from the infant relapse-resistant extinction system to the adult-like relapse-prone extinction system. In addition to exhibiting increased relapse, the expression of extinction in MS P17 rats was also found to be dependent on activation of $\mathrm{GABA}_{\mathrm{A}}$ receptors. As mentioned earlier, the expression of adult extinction memories requires activation of the $\mathrm{GABA}_{\mathrm{A}}$ receptors (41). Similar to studies in adults, when GABAergic inhibition was decreased at an extinction test in juvenile rats (via injection of FG7142), extinction retention was impaired (42). However, in that study FG7142 had no effect on levels of expressed fear in infant rats. That is, infant rats exhibited low levels of freezing at test following extinction regardless of whether they received FG7142 or not. Interestingly, when MS infant rats were given FG7142 at test they behaved similarly to juvenile and adult rats, suggesting that after early stress the role of $\mathrm{GABA}_{\mathrm{A}}$ receptors in extinction expression becomes more adult-like (77). These studies suggest that the development of fear retention and extinction learning, two behaviors with potential importance for vulnerability to mental health disorders (e.g., PTSD), are dynamically regulated by the early life rearing environment (see Table 1 for a summary) and that stress is one condition under which increased vulnerability to mental health problems might emerge.

\section{FGF2}

Another early life event that has been shown to influence the development of fear learning and extinction is exposure to fibroblast growth factor-2 (FGF2). FGF2 is a neurotrophic factor that regulates cell proliferation, differentiation, and survival. During early development FGF2 is responsible for determining the overall morphology of the brain, and during adulthood it is released in response to stress or brain injury, potentially playing a neuroprotective role $(78,79)$. Early life exposure to FGF2 has 
marked central effects; a single peripheral administration of FGF2 on P1 led to increased cell proliferation in the hippocampus, resulting in a larger hippocampal volume that was first evident at $\mathrm{P} 4$ and that persisted throughout adulthood (80). Conversely, transgenic mice that lack FGF Receptor 1 (the primary receptor for FGF2) have decreased hippocampal cell proliferation, resulting in permanent hippocampal atrophy $(80,81)$.

Graham and Richardson (82) investigated whether these longterm hippocampal morphological changes induced by early life exposure to FGF2 might lead to changes in hippocampal-mediated memory formation. They first examined the impact of early life FGF2 on contextual fear conditioning in the developing rat. Infant rats exhibit impaired long-term (i.e., after $24 \mathrm{~h}$ ) memory for contextual fear relative to older rats (83). However, subcutaneous injections of FGF2 from P1-5 led to an early emergence of longterm memory for contextual fear in P16 rats. Early life FGF2 also enhanced contextual fear conditioning in P23 rats, an age at which rats exhibit moderate levels of long-term memory for contextual fear.

Graham and Richardson (82) then examined the impact of early life FGF2 on fear extinction at P16. In those studies, cued fear conditioning procedures were used (i.e., white noise CS paired with shock US) as infant rats can exhibit long-term memory of such associations. Animals were trained in one context, and then extinguished in a different context. Early life FGF2 did not affect the strength of cued fear conditioning, the rate of extinction acquisition, or the retention of extinction training when the extinguished CS was presented in the extinction training context. However, when the extinguished CS was presented in the original fear conditioning context, FGF2-treated P16 rats exhibited recovered fear responses whereas vehicle-treated P16 rats exhibited low fear responses. That is, early life FGF2 led to a precocious emergence of renewal. These results show that early exposure to FGF2 causes an accelerated emergence of the ability to encode and/or maintain a representation of the contextual elements associated with fear conditioning and extinction memories. When taken together with the findings from Cheng et al. (80) it is possible that these behavioral results are a consequence of the effects of early life FGF2 on hippocampal development.

The fact that FGF2, maternal-separation, and exposure to CORT have similar effects, all accelerating the development of fear learning in infant rats, raises the possibility that stress and FGF2 produce their outcomes on early fear learning and extinction through the same or a similar pathway. For example, it might be the case that FGF2 is one of the mechanisms involved in accelerated maturation following early stress. In support of this idea, a large body of evidence has suggested that FGF2 is critically involved in the effects of stress. FGF2 appears to be modulated by activation of the hypothalamic-pituitary-adrenal (HPA) axis, which mediates the mammalian response to stress. Adrenalectomized rats exhibit reduced expression of FGF2 in the hippocampus, striatum, and frontal cortex, whereas administration of glucocorticoids increases FGF2 mRNA in the hippocampus and prefrontal cortex; both results support the idea that adrenal hormones (which are responsible for terminating the stress response) exert control over FGF2 [see review by (84)]. Indeed, both physical and psychological stress upregulate FGF2. Specifically, brain injury leads to increases in FGF2 around the site of the lesion, and application of FGF2 to the lesion reduces cell death and increases astrocytic density (85, 86). Likewise, restraint stress (a psychological stressor) increases FGF2 mRNA expression in the hippocampus and prefrontal cortex (84). These findings point to a potential neuroprotective role for FGF2 in response to stress [see (79)].

There are several factors that determine whether or not FGF2 increases in response to stress, one of which is the controllability of the stressor. Bland et al. (87) exposed two groups of rats to a series of tail shocks. One group could terminate the shock by turning a wheel; the other group were yoked to the first and could not control the shock, but experienced the same number and intensity of shocks as the first group. Escapable, but not inescapable, shock led to a significant increase in hippocampal FGF2 protein expression $2 \mathrm{~h}$ post-shock, and this effect persisted for $24 \mathrm{~h}$. Furthermore, inescapable shock, but not escapable shock, led to a significant decrease in the proliferation of hippocampal neural progenitor cells. A later study demonstrated that escapable shock, but not inescapable shock, also causes increases in FGF2 mRNA expression in the PFC (88). Similarly, Turner et al. (89) reported that chronic (4 days) social defeat stress, in which a rat is exposed to an aggressive male rat of a different strain, down-regulates hippocampal FGF2 mRNA expression. These findings suggest that endogenous FGF2 may protect against the harmful effects of stress (perhaps by increasing cell proliferation), but only if the animal has some level of control over the stressor.

Another factor that determines FGF2's involvement in the stress response is prior exposure to stress hormones. It has been shown that prenatal exposure to corticosterone significantly reduces basal FGF2 mRNA expression during adulthood. Furthermore, prenatal exposure to corticosterone significantly attenuates the upregulation of hippocampal FGF2 mRNA normally seen following acute stress in adulthood (84). Therefore it is possible that early life stress may alter (i.e., cause dysfunctions in) FGF2's neuroprotective response to stress later in life (79).

\section{HOW DO EARLY STRESS AND FGF2 EXPOSURE ACCELERATE THE DEVELOPMENT OF FEAR LEARNING SYSTEMIS?}

One intriguing possibility concerning the effects of stress and FGF2 exposure on accelerated emotional development is that these early experiences regulate the expression of critical period plasticity. Specifically, it is possible that infantile amnesia, impaired context learning, and relapse-resistant extinction represent forms of critical period plasticity in emotional systems, and that these forms of plasticity are controlled by the same cascade of signals as critical periods in other areas of the brain. That is, stress exposure could initiate a cascade of cellular and molecular changes involved in terminating infant-like forms of fear learning via HPA activation of FGF2 receptors. This would be an attractive, and simple, explanation for the similar outcomes of early stress and FGF2 exposure on developmental transitions in fear learning. In other words, it is possible that stress and FGF2 activate a "signature" set of signals involved in critical period termination across the brain.

Traditionally, critical/sensitive periods have been defined as discrete stages of rapid neural development in which plasticity is enhanced, allowing early environmental input to fine-tune final wiring patterns in the brain before plasticity is reduced in 
adulthood [e.g., (90-92)]. The onset and offset of critical periods is not a simple age-dependent maturational process. Rather, the timing of critical periods can be manipulated by different experiences which affect the various molecular and cellular signals involved in their opening and closure (90). While the high levels of plasticity inherent in a critical period allow for enhanced learning and refinement of neural functions these periods also represent a time of vulnerability for the developing brain. If aberrant sensory or social events are experienced, or expected environments do not manifest, then the timing and function of the critical period can be altered, placing the brain at risk for abnormal wiring patterns and adverse behavioral/sensory outcomes. For instance, some developmental disorders in humans (e.g., autism) have been proposed to result from a disruption in the timing or expression of critical periods across various brain regions $(93,94)$.

There are many different critical periods which occur across development, each involving unique brain regions or neural circuits (95). For example, critical periods in humans have been proposed for the development of sensory/sensory-motor, cognitive, and emotion systems [e.g., $(4,7,96,97)]$. For instance, when learning takes place before the age of 7 years, acquisition of a second language usually occurs to a level that is grammatically indistinguishable from that of native speakers. However, mastery of a second language becomes progressively harder from 8 years onward $(98,99)$. Other research has shown that children need to be exposed to appropriate levels of cognitive, tactile, and emotional stimulation early in life in order to develop adequate cognitive functions and emotion regulation skills. Children reared in institutional settings which lack the appropriate levels of stimulation exhibit profound deficits in cognitive and emotional development, effects which are often permanent if children are not adopted before the age of 2 years [see (3), for a review; (100)].

In non-human animals critical/sensitive periods have also been shown to occur in a variety of sensory and emotional systems, such as song learning in birds, attachment learning in rats, and cortical responses to vibrissa stimulation in rats [see (101-103), for a review; $(71,104,105)]$. The best characterized animal model of critical period plasticity, however, is that of ocular dominance (OD) plasticity induced by monocular deprivation $[(106,107)$; see $(91,108)$, for reviews; see also (92), for a review]. Only during the critical period for OD plasticity does closure of one eye result in a loss of visual acuity in the closed eye (amblyopia) and a shift in the responsiveness of neurons in the primary visual cortex away from the closed eye.

Research investigating OD plasticity has highlighted numerous molecular and cellular signals which are involved in opening and closing this critical period. Importantly, these signals have been shown to regulate the timing of sensitive periods in other sensory modalities $(104,105)$, suggesting that there may be a general neural signature which guides critical period timing across the brain. Although the neural signature for critical period timing has mostly been investigated in sensory systems, recent evidence suggests that the same signals may also regulate sensitive periods in fear learning (46). Further, there is some evidence to suggest that those neural signals are regulated by particular types of early experience, suggesting a potential mechanism via which stress/CORT/FGF2 may have affected the timing of adult-like fear retention, context learning, and extinction described earlier. While a detailed analysis of the molecular and cellular events involved in triggering the onset and offset of critical period plasticity in the visual cortex is beyond the scope of this review [interested readers are referred to excellent past reviews on the topic: $(91,92,108)]$, we provide a brief summary of those molecular and cellular signals important for critical period plasticity in the visual system that also may have a role in fear and extinction learning and that appear to be regulated by stress/CORT/FGF2.

\section{SIGNALS INVOLVED IN THE OPENING OF CRITICAL PERIOD PLASTICITY}

The onset of OD plasticity appears to be triggered by a change in the balance of excitation and inhibition in the visual cortex, mostly as a result of developmental increases in inhibitory activity. For example, 4 days of monocular deprivation starting on P25-P27 induces OD plasticity in wild-type mice but not in mice with a genetic knockout (KO) of the GAD65 gene, which inhibits GABA release. However, critical period plasticity could be rescued in GAD65 KO mice if levels of inhibition were artificially increased during monocular deprivation via infusion of a benzodiazepine directly into the visual cortex (109). Benzodiazepines were also successful in precociously inducing OD plasticity when monocular deprivation was performed in pre-critical period mice [P15-P20; (90)]. It appears that the maturation of intra-cortical inhibition is regulated by brain derived neurotrophic growth factor (BDNF) because genetic over-expression of BDNF across postnatal development accelerated the maturation of parvalbumin positive $(\mathrm{PV}+)$ GABAergic interneurons in the visual cortex and resulted in a precocious critical period $(110,111)$. Together these studies suggest that the molecular machinery for enhanced plasticity is present early in life but that maturation in GABAergic circuitry (e.g., PV+ interneurons and GABAergic synapses) pushes inhibitory activity beyond a certain threshold to trigger the opening of the critical period.

\section{SIGNALS INVOLVED IN THE CLOSURE OF CRITICAL PERIOD PLASTICITY}

While intra-cortical inhibition appears to be sufficient for the initiation of critical period plasticity, there are several mechanisms that appear to be involved in critical period termination, many acting as "structural brakes" which limit plasticity. For example, critical periods appear to be regulated by the appearance of extracellular matrix proteins - perineuronal nets (PNNs) - around the dendrites, axons, and cell bodies of GABAergic neurons. PNNs are believed to limit critical period plasticity by increasing stability of synapses via inhibition of axonal growth and sprouting. Appearance of PNNs in various brain regions correlates with termination of critical period plasticity in several different sensory systems [e.g., $(92,104,105,108)]$, and recently appearance of PNNs in the amygdala was shown to correlate with the termination of infant-like, relapse-resistant extinction learning and the transition into adult-like, relapse-prone extinction learning (46). Interestingly, when PNNs in the visual cortex or amygdala of adult rats are degraded via chondroitinase $\mathrm{ABC}$ (chABC), then the critical periods for OD plasticity and erasure-like extinction, respectively, are reopened $(46,112)$. This research strongly suggests that erasure-like extinction represents a form of critical period plasticity occurring in emotion circuits in the brain, and that 
termination of this form of infant plasticity appears to be regulated by some of the same structural brakes as critical period plasticity in sensory systems.

In addition to the formation of PNNs, other developmental factors also appear to be involved in limiting structural plasticity in the visual cortex and terminating the critical period for OD plasticity. For example, maturation of myelin basic protein (MBP) in the visual cortex has been shown to correlate with termination of the critical period for OD plasticity (113), potentially through inhibiting mechanisms of structural remodeling necessary for plasticity (114). The myelin associated growth inhibitor Nogo-66 is known to limit axonal regeneration following CNS damage because antagonizing the Nogo-66 receptor (NgR) promotes axonal regeneration following spinal cord injury in the rat (115). Interestingly, when the NgR was genetically deleted in mice and monocular deprivation occurred post-sensitive period (i.e., at $\mathrm{P} 45)$ the mutant mice exhibited OD plasticity whereas wildtype mice did not (113). Hence, it appears that adult mice retain the capacity for enhanced plasticity but that increased myelination in the visual cortex which occurs across development acts as a structural brake, limiting OD plasticity.

Another factor that has been implicated in the closure of the critical period for OD plasticity is calcium/cAMP response element binding protein (CREB)-mediated gene transcription. Evidence for the role of CREB activity in OD plasticity comes from studies which have shown that monocular deprivation during the critical period stimulates CREB-mediated gene transcription whereas post-critical period monocular deprivation has a less pronounced effect on CREB-mediated processes (116). Further, when CREB activity is enhanced in adult mice (through the use of a transgenic mouse line expressing VP16-CREB, which leads to constitutively active CREB across life), it has been shown that persistent OD plasticity can be induced in the visual cortex (117). Also, inhibiting upstream regulators of CREB (e.g., PKA) in cats decreases OD plasticity during the critical period (118).

It has been proposed that CREB is important in terminating critical periods because it regulates the activity of plasticitymodulating genes (92). Studies examining candidate CREBmediated genes that might be involved in OD plasticity have focused on micro RNA (mir) 132 which has been implicated in neural plasticity (119). In a recent study, increasing mir132 expression in mice before monocular deprivation blocked OD plasticity during the critical period (120), suggesting that mir132 acts as a brake on plasticity.

\section{STRESS, CORTICOSTERONE, AND FGF2 REGULATE MOLECULAR AND CELLULAR SIGNALS INVOLVED IN CRITICAL PERIOD TIMING}

Early exposure to stress, corticosterone, and FGF2 has been shown to accelerate the transition into adult-like fear retention and extinction learning in infant rats; early exposure to those events led to a precocious termination of the critical period for infantile amnesia and erasure-like extinction. It is possible that stress/CORT/FGF2 exposure hastened the developmental transitions in fear learning by acting on those processes known to be involved in critical period regulation in other systems. Indeed, evidence shows that early life adversity, CORT, and FGF2 regulate many of the molecular and cellular signals involved in both the opening and the closure of critical periods, accelerating the developmental emergence of those signals in brain regions important for emotional responding in adults. However, those rodent studies which examined environmental regulation of infant fear retention and extinction only measured outcomes at one time point making a determination of the early closure of the critical period possible but determination of an early opening of the critical period uncertain. It could be the case that the critical period for infantile amnesia and erasure-like extinction opened at the same time in MS/CORT/FGF2 and SR/vehicle rats, but that this period closed earlier in the MS/CORT/FGF2 rats (i.e., the time frame for the critical period was compressed). Alternatively, it may be the case that MS/CORT/FGF2 led to an early opening as well as an early closure of the critical period (see Figure 1 for a depiction of these possibilities). The fact that stress and FGF2 appear to regulate signals involved in both the opening and closure of critical periods, however, suggests that the latter case is most likely the case (i.e., that stress/FGF2 leads to an early opening and closure of the critical period in fear learning).

Evidence that stress might regulate critical period opening in the emotional system comes from studies examining the effect of early stress on GABAergic development. Specifically, maternal-separation has been shown to lead to a more mature

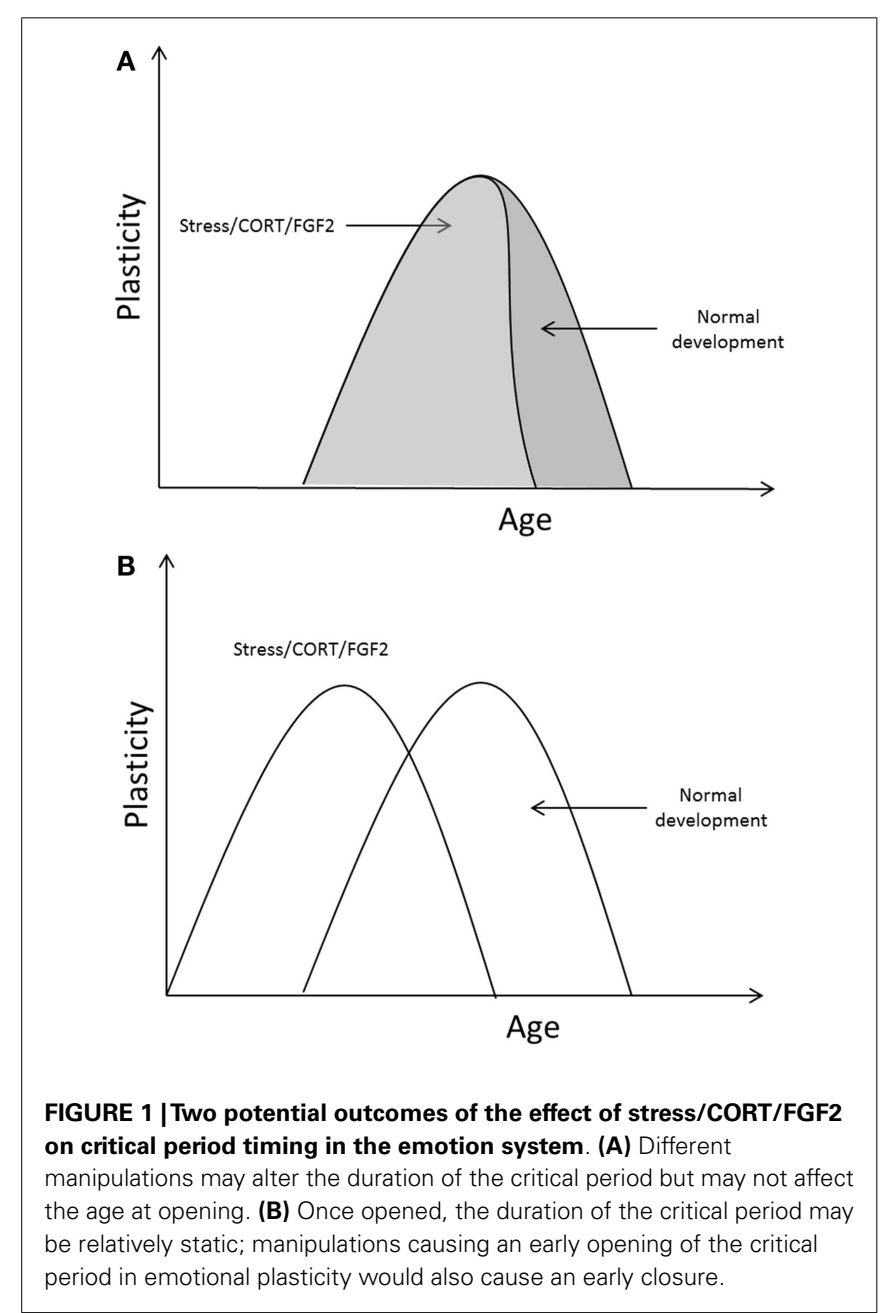


form of GABAergic signaling in the CA1 region of the infant hippocampus of male rats (121), and maternally separated rats also exhibit a short-term upregulation of BDNF in the PFC and hippocampus at P17 (122). As mentioned earlier, the critical period for OD plasticity is triggered by maturation of GABA in the visual cortex. Further, early over-expression of BDNF in the visual cortex was shown to accelerate GABAergic maturation and lead to a precocious emergence of OD plasticity.

In addition to influencing signals involved in the opening of critical periods, early life stress/corticosterone/FGF2 also appear to regulate some of the structural brakes on plasticity. For example, early life stress (caused by weaning rats at P14 rather than P21) has been shown to accelerate whole-brain, as well as amygdala-specific, myelination in P21-P35 male mice $(123,124)$. Also, elevated glucocorticoids have been shown to accelerate the initiation and rate of myelination in co-cultures of Schwann-cell and neurons taken from infant rats (125). In addition, oligodendrocyte cells express FGF receptors, and FGF2 application to cultured cells stimulates proliferation of oligodendrocyte precursor cells (126). FGF2 has also recently been identified as a critical regulator of myelin sheath thickness. Furusho et al. (127) created a line of mutant mice that lacked the FGF receptors 1 and 2, the two receptors to which FGF2 binds. They reported that while mutant mice exhibited normal initiation of myelination in the spinal cord at P4 (as judged by immunoblotting for MBP), by P30 mutant mice exhibited significantly less MBP positive myelin, and reduced overall white matter area, compared to control mice, suggesting a reduction in myelin synthesis. Accordingly, while myelin thickness increased from P15 to 10 months of age (the oldest age tested) in control mice, myelin thickness stalled in mutant mice, who exhibited thinner myelin compared to control mice from PND 30 to 10 months of age. Importantly, the numbers of myelinated and unmyelinated axons was comparable in control and mutant mice at all ages tested, suggesting that FGF2 plays a specific role in signaling for the development of myelin thickness. Hence, it is possible that early life exposure to FGF2, stress, or to stress hormones may help to precociously terminate critical periods in fear learning via accelerating the rate of myelin development in the hippocampus, amygdala, and $\mathrm{mPFC}$.

Along with potentially accelerating structural brakes in plasticity, it is also possible that early life stress/CORT/FGF2 exposure caused an early termination of infantile amnesia, impaired context learning, and erasure-like extinction via a CREB-mediated pathway. For example, many of FGF2's neurotrophic effects appear to be mediated by phosphorylation of CREB. Sung et al. (128) showed that FGF2 increases hippocampal neuronal differentiation and outgrowth via causing phosphorylation of CREB and CREmediated gene transcription. They also demonstrated that FGF2induced neuronal outgrowth was blocked in cells that contained a dominant negative CREB construct (blocking CREB activation). FGF2 also appears to regulate hippocampal cell proliferation via phosphorylation of CREB (129), and FGF2-induced cell proliferation is blocked by a CREB inhibitor. Cell proliferation was markedly increased in cell cultures that over-expressed CREB, but only if FGF2 was applied to these cultures. In other words, CREB over-expression did not increase cell proliferation by itself, suggesting that FGF2 recruits CREB to increase cell proliferation. In addition, recent research has shown that early exposure to stressors (e.g., maternal-separation) regulates the expression of non-coding RNAs which are mediated by CREB. Specifically, Uchida et al. (130) showed that MS180 from P2 to P14 increased the expression of mir132 in the PFC of P14 mice relative to SR P14 mice. Furthermore, FGF2 has been shown to upregulate mir132 in cultured immature cortical neurons, as well as in cultured astroglial cells (131). As mentioned earlier, alterations in the expression of mir132 have been shown to regulate critical period timing for OD plasticity.

Together the findings just reviewed suggest that early life exposure to FGF2/stress/CORT may regulate the developmental timing of critical periods in fear learning via accelerated maturation of BDNF expression, GABAergic inhibition, myelination, and CREBmediated gene transcription in those brain regions critical for fear memory and extinction learning in adults - the hippocampus, mPFC, and amygdala (see Figure 2). If this were true, it would

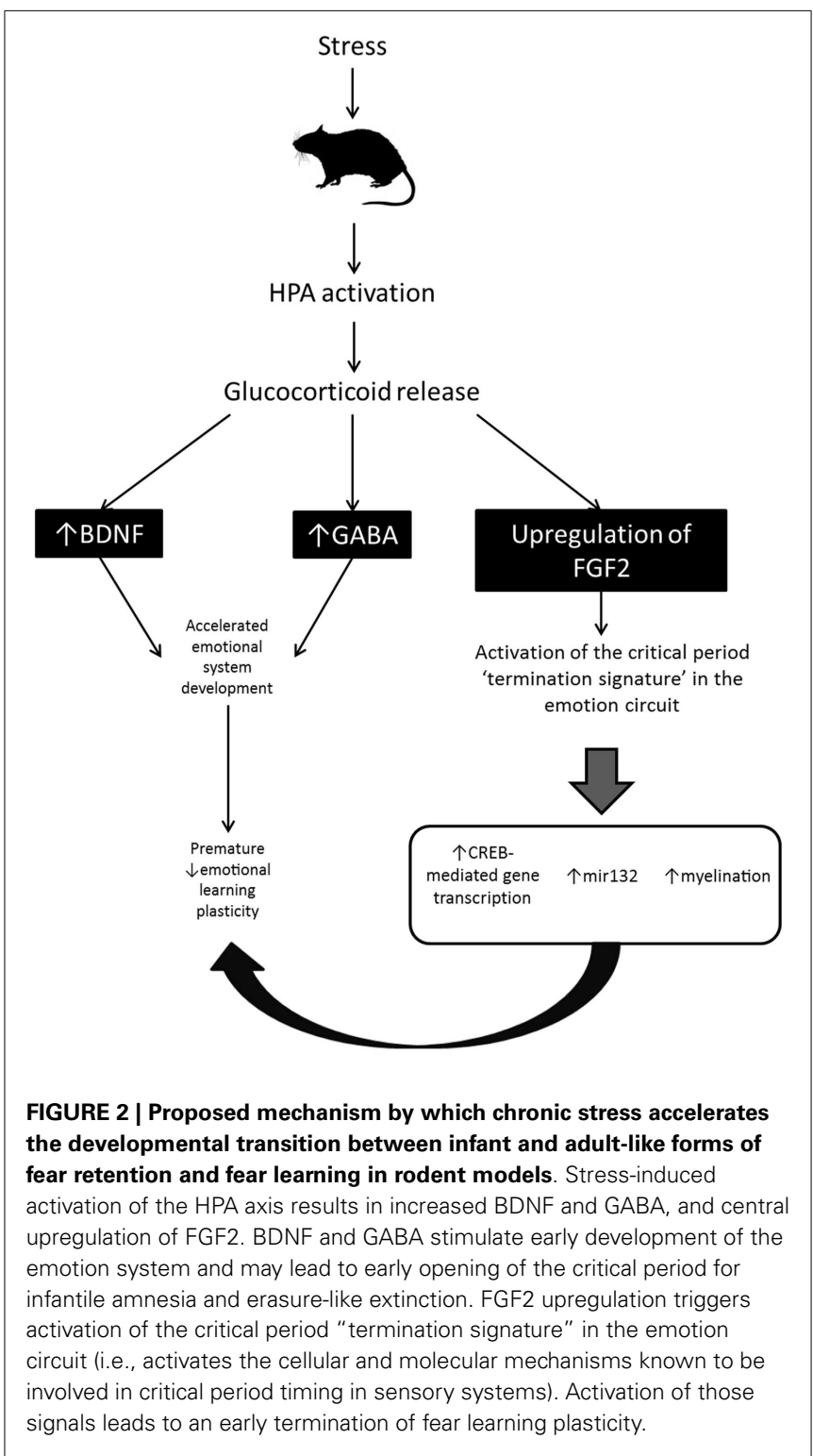


support the idea that there may be a common neural signature which guides critical periods of plasticity across the brain. This idea has been raised by previous researchers to explain the finding that the same molecular and cellular signals appear to be involved in a variety of critical periods in different sensory systems (108). However, the idea that the same molecular and cellular signals may regulate critical periods of plasticity for fear learning in subcortical circuits (e.g., the amygdala) has only recently begun to be explored [e.g., (46)].

\section{POTENTIAL FOR MULTIGENERATIONAL EFFECTS OF STRESS/FGF2 ON FEAR LEARNING}

If critical period mechanisms are involved in regulating the opening and closure of fear learning plasticity then a potential implication is that the effects of environmental manipulations on maturation of fear learning might be heritable. Indeed, epidemiological evidence suggests that the effects of stress on mental health can be transmitted across multiple generations. For instance, mothers that were exposed to the September 11 terrorist attacks in New York City during pregnancy and who subsequently developed PTSD were shown to exhibit a suppressed basal cortisol response (132). Interestingly, a similar profile of cortisol suppression was also evident in the infants of those mothers, with that being especially true for infants of mothers that were in the third trimester of pregnancy when the attacks occurred. In addition, high risk phenotypic traits for mental health problems (e.g., behavioral inhibition) have been shown to exhibit a high degree of heritability, which can be attributed to both genetic and environmental factors (133-136). Hence, there is clear epidemiological data suggesting that mental health disorders and the influence of stress on the emergence of those disorders is heritable.

Animal models have been increasingly used to investigate the intergenerational transmission of neurobehavioral alterations after stress (137-140). Several studies in rodents have shown that stress-evoked alterations in parenting style are passed onto offspring, and that these behavioral alterations are often accompanied by neuroendocrine changes (141). In addition, epigenetic modifications to gene transcription caused by early life stress have been shown to persist across the life of the rat and to be passed onto biological offspring (137). Interestingly, more recent studies have demonstrated that actual stress-induced behavioral phenotypes can also be transmitted across generations. For example, maternally separated rats exhibited depressed behaviors as adults, and these same depressive behaviors were also exhibited by their adult offspring and grandchildren, despite those subsequent generations never being exposed to stress (138). Hence, animal research has been useful in modeling the transmission of both neurological as well as behavioral alterations caused by stress. One currently unexplored possibility is that stress-induced alterations to the maturation of fear retention and extinction systems could also be transmitted to subsequent generations. Indeed, some of the mechanisms involved in critical period opening and closure could potentially lead to such a transgenerational profile. Specifically, research has shown that transgenerational effects can be produced by alteration of cytoplasmic RNAs (e.g., miRNA), which can be carried in the sperm and eggs and can epigenetically alter the phenotype of subsequent offspring. Recently it has been proposed that miRNAs may be important in the transmission of environmentally induced phenotypic changes across generations because some RNAs can survive degradation during embryogenesis and have been shown to regulate offspring phenotype [e.g., (142)]. The evidence for this comes from experiments which show that injection of a miRNA critical for brain development [mir124; $(119,143)]$ directly into cell embryos resulted in offspring which exhibited a much faster growth rate (increased by $30 \%$ ) than noninjected offspring (144). Importantly, this "giant" phenotype was transmitted across multiple generations via alterations of mir124 in the spermatozoa. Hence, changes in the expression levels of certain miRNAs can be incorporated into the germ-line of animals and produce a transgenerational phenotype. As mentioned earlier, a recent study showed that a miRNA important for inhibiting OD plasticity in the visual cortex (mir132) and the miRNA which produced a transgenerational "giant" phenotype (mir124) was upregulated in the mPFC of P14 mice following maternalseparation (130). Further, mir132 is upregulated by FGF2 (131). Hence, it is possible that the expression of these miRNAs may regulate critical period closure in fear learning systems and that stress/FGF2-induced alterations in these miRNAs could be heritable. Such hypotheses will need to be investigated in future studies.

\section{BRIDGING THE GAP BETWEEN BASIC AND CLINICAL WORK: CLINICAL IMPLICATIONS AND POTENTIAL TRANSLATION OF STRESS/FGF2-INDUCED ACCELERATION OF EMOTIONAL DEVELOPMENT IN ANIMAL MODELS}

The fact that infantile amnesia and relapse-resistant extinction are regulated by stress, FGF2, and potentially other early life events is highly relevant for clinical researchers working on understanding and treating mental health disorders across the lifespan. Early life stress is one of the greatest contributing risk factors for mental health problems across all life stages (145), relating not only to risk for mental health disorders but also to transdiagnostic features common of many psychological disorders [e.g., increased emotional reactivity; $(146,147)]$. Further, early adversity and abuse has been shown in human populations to interact with specific genetic polymorphisms to predict adult major depressive disorder and PTSD $(148,149)$. However, the developmental trajectories which are altered by such gene $x$ environment interactions remain elusive. The body of research reviewed in this paper suggests that early emerging changes in fear learning and extinction resulting from stress may be one outcome which could affect emotional responding across the lifespan and which might interact with genetics to produce stable phenotypes of risk for mental health disorders. For example, it is possible that stress exposure during a critical period of development early in life paired with a later experienced trauma might lead to a phenotype of treatment-resistant PTSD in genetically predisposed individuals via a pathway of altered development of the fear extinction system; such a possibility should be examined in future studies.

The possibility that infantile amnesia and relapse-resistant extinction may represent critical period plasticity in fear learning also has significant clinical implications, especially when considering potential pharmacological treatments for mental health disorders. As discussed earlier, the involvement of critical period 
molecular signals in terminating fear learning plasticity opens up a possible mechanism via which the effects of stress/FGF2 exposure might increase vulnerability for mental health problems across multiple generations. In addition, they also suggest several novel mechanisms via which anxiety disorders and other mental health problems might be treated. Specifically, if critical periods of emotional learning could be reopened in adulthood (or at any point after they have closed) it may help treat the root of many anxiety disorders (i.e., persistent expression of fear and relapse after extinction). In other words, it is possible that anxious individuals might be treated with pharmacological adjuncts to reopen infantlike forgetting and relapse-resistant extinction, which could then be combined with therapy to improve treatment efficacy. Indeed, there have been three recent studies which suggest that the critical period of erasure-like (relapse-resistant) extinction can be reopened in juvenile and adult rats. The first evidence that relapseresistant/erasure-like extinction could be reactivated in adult rats came from Gogolla et al. (46). In those studies appearance of PNNs around GABAergic amygdala interneurons was correlated with the natural transition from relapse-resistant extinction in infant mice to relapse-prone extinction in juvenile mice. That is, at the same time that rats began to exhibit relapse behaviors after extinction there was a significant increase in the number of PNNs in the amygdala. To examine whether the formation of the PNNs was sufficient to cause the transition into adult-like extinction Gogolla et al. degraded amygdala PNNs with chABC in adult mice before conditioning. The treatment with chABC significantly reduced the number of PNNs in the adult amygdala and also reduced the expression of relapse behaviors after extinction (i.e., the chABCtreated adults did not show renewal or spontaneous recovery of extinguished fear). Hence, it appears that the infant profile of extinction learning could be reactivated in adulthood by removal of one of the structural brakes on plasticity - PNNs.

Another line of evidence that "erasure-like" extinction can potentially be activated in adult rats comes from recent work on the impact of acute, exogenous FGF2 on extinction of conditioned fear (150-153). Those studies demonstrated that systemic or intra-amygdala infusion of FGF2 not only enhanced extinction in juvenile and adult rats, but it also significantly reduced renewal and reinstatement, even when vehicle-treated rats were given four times the amount of extinction training to match extinction strength between vehicle- and FGF2-treated groups. In other words, when treated with FGF2, adult rats exhibit the behavioral qualities of infant-like (erasure-like) extinction. The neurobiological mechanisms by which FGF2 causes infant-like extinction are unknown. Nevertheless, similar to findings in the visual system, it appears that adult rats retain the capacity for infant-like extinction and that this form of plasticity can be reactivated rapidly under conditions which favor that plasticity.

In order to investigate the possibility that extinction combined with FGF2 leads to an erasure of the original fear memory, Graham and Richardson (152) exploited recent findings regarding re-extinction, which refers to the process of relearning extinction following reacquisition of fear to an extinguished cue. Converging evidence strongly suggests that whereas initial extinction in adult rats is impaired by NMDAr antagonists, re-extinction is not impaired by NMDAr antagonists (154-157). This suggests that relearning to extinguish fear does not depend on NMDAr activity. However, Graham and Richardson (152) found that when rats were systemically injected with FGF2 immediately after extinction training, then retrained to fear the extinguished CS, and then re-extinguished following treatment with an NMDAr antagonist, FGF2-treated rats exhibited impaired re-extinction retention. In contrast, rats that were extinguished with vehicle and then reextinguished following treatment with an NMDAr antagonist did not exhibit any impairment in re-extinction retention. That is, during re-extinction FGF2-treated rats "behaved" as if the CS was being extinguished for the first time. Interestingly, similar results have been obtained for juvenile rats that are extinguished to a CS at PND 16 (during the "erasure-like extinction" period of development), and then retrained and re-extinguished to the same CS later in development. In this instance, re-extinction is also NMDAr-dependent (158). Together, these findings suggest that FGF2 treatment, when combined with extinction training, may reactivate the "erasure-like" fear extinction observed in infant rats.

The third study to attempt to reactive infant-like plasticity in rodents during extinction learning was performed by Karpova et al. (159). In that study adult mice were chronically exposed to the antidepressant fluoxetine in their drinking water either before or after fear conditioning and during extinction and test. They showed that the fluoxetine-exposed mice behaved like infant mice in past studies (46), showing less post-extinction relapse than the vehicle-treated mice. In addition, fluoxetine treatment also resulted in a lower proportion of PNNs in the BLA, suggesting that the effect of fluoxetine on relapse behaviors after extinction may have occurred through facilitating the removal of structural brakes on plasticity (PNNs). Interestingly, combining antidepressant treatments like fluoxetine with exposure therapy in humans has often yielded better results than either treatment alone (160). The study by Karpova et al. (159) suggests that fluoxetine-induced reactivation of the critical period for erasure-like extinction might underlie those clinical findings.

\section{CONCLUSION}

The findings regarding accelerated development of fear learning by stress/CORT/FGF2 are theoretically relevant because they demonstrate that the rate at which particular forms of learning and memory mature across the lifespan can be influenced by a range of early life experiences. Until recently, no one had examined how early experiences affected fear retention and extinction development, despite these forms of emotional learning being critically involved in the pathogenesis and treatment of mental health problems. The studies reviewed here show that the timing of the maturation of fear learning is not set in stone but can be dynamically regulated by early experience. In addition, these findings are clinically relevant because early life adversity is a common feature in persons with psychopathology [e.g., $(161,162)]$, and fear retention and extinction in rats are important pre-clinical models of anxiety problems in humans $(10,163,164)$. Although many theories have suggested that early experiences are critical for the emergence of anxiety and other mental health problems in humans (165-168), no studies, until very recently, had examined how fear retention and extinction are impacted by different early experiences in infant rodents. In addition, within the human literature, 
there are reports of individual differences in the processes of fear retention and extinction which may underlie subsequent vulnerability to develop anxiety problems [e.g., $(169,170)]$, yet there is little information on what factors might influence those differences or the molecular mechanisms which might underlie them.

While the findings regarding environmental alteration of the maturation of fear learning systems are novel, at this stage there are no definitive answers about what molecular and cellular mechanisms drive the normal development of these emotion systems, nor the accelerated transition produced by stress/CORT/FGF2. However, the fact that all three manipulations have a similar effect on emotion system development, that stress/CORT regulate FGF2, and that stress/CORT and FGF2 appear to regulate some of the signals involved in critical periods of plasticity in sensory systems hints at a potential mechanism for transitions in fear learning. Specifically, we have suggested that the expression of infantile amnesia and relapse-resistant extinction in infancy may represent critical period plasticity and propose a model in which early environments that alter the age at which the developmental transitions occur (e.g., stress) might function through an HPA/FGF2-dependent activation of "critical period signals," in turn leading to an early termination in emotional plasticity (see Figure 2 for a graphical depiction of this model). The proposed model, although speculative, does suggest some potential avenues for future research. Specifically, if the principles guiding critical

\section{REFERENCES}

1. Repetti RL, Taylor SE, Seeman TE. Risky families: family social environments and the mental and physical health of offspring. Psychol Bull (2002) 128:330-66. doi: 10.1037/0033-2909.128.2.330

2. McLaughlin KJ, Gomez JL, Baran SE, Conrad CD. The effects of chronic stress on hippocampal morphology and function: an evaluation of chronic restraint paradigms. Brain Res (2007) 1161:5664. doi:10.1016/j.brainres.2007.05. 042

3. Nelson CA, Zeanah CH, Fox NA, Marshall PJ, Smyke AT, Guthrie D. Cognitive recovery in socially deprived young children: the Bucharest Early Intervention Project. Science (2007) 318:193740. doi:10.1126/science.1143921

4. Zeanah C, Egger H, Smyke A, Nelson C, Fox N, Marshall P, et al. Institutional rearing and psychiatric disorders in Romanian preschool children. Am J Psychiatry (2009) 166:777-85. doi:10. 1176/appi.ajp.2009.08091438

5. Taylor SE, Way BM, Seeman TE. Early adversity and adult health outcomes. Dev Psychopathol (2011) 23:939-54. doi:10.1017/ S0954579411000411

6. Bock J, Gruss M, Becker S, Braun K. Experience-induced changes of dendritic spine densities in

period plasticity in sensory systems can also be generalized to emotion learning, it should be possible to manipulate the timing of infantile amnesia and erasure-like extinction via alteration of any of the signaling pathways involved in critical period plasticity in sensory systems. Also, interfering with any of the signaling pathways involved in critical period plasticity should change the effect of stress on fear retention and extinction learning in infant rats. One possibility, for example, might be to chronically suppress levels of BDNF while rats are experiencing maternal-separation to determine whether accelerated emergence of adult-like fear retention and extinction still occurs. All these possibilities would have important outcomes both theoretically, in understanding the guiding principles of critical period plasticity, as well as clinically, in understanding how particular experiences might impact emotional development across the life span. Although these speculations require further examination, the reviewed literature is clearly developing a foundation for examining the experiencedependent modulation of critical period opening and closure in emotional systems, an area with significant implications for our understanding and treatment of anxiety disorders (e.g., PTSD).

\section{ACKNOWLEDGMENTS}

Preparation of this manuscript was supported by Grants from the Australian Research Council (DP0985554, DP120104925) to Rick Richardson.

reduced recall for fear extinction in PTSD: results of a twin study. J Psychiatr Res (2008) 42:51520. doi:10.1016/j.jpsychires.2008. 01.017

12. Milad MR, Pitman RK, Ellis CB, Gold AL, Shin LM, Lasko NB, et al. Neurobiological basis of failure to recall extinction memory in posttraumatic stress disorder. Biol Psychiatry (2009) 66:1075-82. doi:10. 1016/j.biopsych.2009.06.026

13. Campbell BA, Campbell EH. Retention and extinction of learned fear in infant and adult rats. J Comp Physiol Psychol (1962) 55:1-8. doi:10.1037/h0049182

14. Campbell BA, Spear NE. Ontogeny of memory. Psychol Rev (1972) 79:215-36. doi:10.1037/h0032690

15. Kim JH, McNally GP, Richardson R. Recovery of fear memories in rats: role of gamma-amino butyric acid (GABA) in infantile amnesia. Behav Neurosci (2006) 120: 40-8. doi:10.1037/0735-7044.120. 1.40

16. Yap CSL, Richardson R. Extinction in the developing rat: an examination of renewal effects. Dev Psychobiol (2007) 49:565-75. doi:10. 1002/dev.20244

17. Kim JH, Richardson R. New findings on extinction of conditioned fear early in development: theoretical and clinical implications. Biol Psychiatry (2010) 67:297-303. doi:10.1016/j.biopsych.2009.09.

003

18. Kim JH, Li S, Hamlin AS, McNally GP, Richardson R. Phosphorylation of mitogenactivated protein kinase in the medial prefrontal cortex and the amygdala following memory retrieval or forgetting in developing rats. Neurobiol Learn Mem (2012) 97:59-68. doi:10.1016/j.nlm.2011.09.005

19. Blanchard RJ, Blanchard DC. Passive and active reactions to feareliciting stimuli. J Comp Physiol Psychol (1969) 68:129. doi:10. 1037/h0027676

20. Gale GD, Anagnostaras SG, Godsil BP, Mitchell S, Nozawa T, Sage JR, et al. Role of the basolateral amygdala in the storage of fear memories across the adult lifetime of rats. J Neurosci (2004) 24:38105. doi:10.1523/JNEUROSCI.410003.2004

21. Campbell BA, Jaynes J, Misanin JR. Retention of a light-dark discrimination in rats of different ages. J Comp Physiol Psychol (1968) 66:467. doi:10.1037/h0026360

22. Feigley DA, Spear NE. Effect of age and punishment condition on long-term retention by the rat of active-and passive-avoidance learning. J Comp Physiol Psychol (1970) 73:515. doi:10.1037/ h0030234 
23. Spear NE, Rudy JW. Tests of the Ontogeny of Learning and Memory: Issues, Methods, and Results. New York, NY: Oxford University Press. (1991).

24. Hayne H. Infant memory development: implications for childhood amnesia. Dev Rev (2004) 24:33-73. doi:10.1016/j.dr.2003.09.007

25. Campbell BA, Jaynes J. Reinstatement. Psychol Rev (1966) 73:47880. doi:10.1037/h0023679

26. Spear NE, Parsons PJ. Analysis of a reactivation treatment: ontogenetic determinants of alleviated forgetting. In: Medin DL, Roberts WA, Davis RT, editors. Processes of Animal Memory. Hillsdale, NJ: Erlbaum (1976). p. 135-65.

27. Rovee-Collier C. Dissociations in infant memory: rethinking the development of implicit and explicit memory. Psychol Rev (1997) 104:467. doi:10.1037/0033295X.104.3.467

28. Tang HH, McNally GP, Richardson R. The effects of FG7142 on two types of forgetting in 18-day-old rats. Behav Neurosci (2007) 121:1421-4. doi:10.1037/ 0735-7044.121.6.1421

29. Harris JA, Westbrook RF. Benzodiazepine-induced amnesia in rats: reinstatement of conditioned performance by noxious stimulation on test. Behav Neurosci (1998) 112:183-92. doi:10.1037/0735-7044.112.1.183

30. Bouton ME, Bolles RC. Contextual control of the extinction of conditioned fear. Learn Motiv (1979) 10:445-66. doi:10. 1016/0023-9690(79)90057-2

31. Milad MR, Orr SP, Pitman RK, Rauch SL. Context modulation of memory for fear extinction in humans. Psychophysiology (2005) 42:456-64. doi:10.1111/j. 1469-8986.2005.00302.x

32. Bouton ME, Bolles RC. Role of conditioned contextual stimuli in reinstatement of extinguished fear. J Exp Psychol Anim Behav Process (1979) 5:368-78. doi:10. 1037/0097-7403.5.4.368

33. Schiller D, Cain CK, Curley NG, Schwartz IS, Stern SA, LeDoux $\mathrm{JE}$, et al. Evidence for recovery of fear following immediate extinction in rats and humans. Learn Mem (2008) 15:394-402. doi:10. 1101/lm.909208

34. Quirk GJ. Memory for extinction of conditioned fear is longlasting and persists following spontaneous recovery. Learn Mem (2002) 9:402-7. doi:10.1101/lm. 49602
35. Miserendino MJD, Sananes CB, Melia KR, Davis M. Blocking of acquisition but not expression of conditioned fear-potentiated startle by NMDA antagonists in the amygdala. Nature (1990) 345:7168. doi:10.1038/345716a0

36. Falls WA, Miserendino MJ, Davis M. Extinction of fear-potentiated startle: blockade by infusion of an NMDA antagonist into the amygdala. J Neurosci (1992) 12:854-63.

37. Laurent V, Westbrook RF. Infusion of the NMDA receptor antagonist, DL-APV, into the basolateral amygdala disrupts learning to fear a novel and a familiar context as well as relearning to fear an extinguished context. Learn Mem (2009) 16:96-105. doi:10.1101/lm. 1218709

38. Walker DL, Ressler KJ, Lu K-T, Davis M. Facilitation of conditioned fear extinction by systemic administration or intra-amygdala infusions of D-cycloserine as assessed with fear-potentiated startle in rats. J Neurosci (2002) 22:2343-51.

39. Ledgerwood L, Richardson R, Cranney J. Effects of Dcycloserine on extinction of conditioned freezing. Behav Neurosci (2003) 117:341-9. doi:10.1037/0735-7044.117.2.341

40. Ledgerwood L, Richardson R, Cranney J. D-cycloserine and the facilitation of extinction of conditioned fear: consequences for reinstatement. Behav Neurosci (2004) 118:505-13. doi:10.1037/ 0735-7044.118.3.505

41. Harris JA, Westbrook RF. Evidence that GABA transmission mediates context-specific extinction of learned fear. Psychopharmacology (Berl) (1998) 140:105-15. doi:10. 1007/s002130050745

42. Kim JH, Richardson R. A developmental dissociation of context and GABA effects on extinguished fear in rats. Behav Neurosci (2007) 121:131-9. doi:10. 1037/0735-7044.121.1.131

43. McNally GP, Westbrook RF. Opioid receptors regulate the extinction of Pavlovian fear conditioning. Behav Neurosci (2003) 117:1292301. doi:10.1037/0735-7044.117.6. 1292

44. Kim JH, Richardson R. The effect of the $\mu$-opioid receptor antagonist naloxone on extinction of conditioned fear in the developing rat. Learn Mem (2009) 16:161-6. doi:10.1101/lm.1282309

45. Kim JH, Richardson R. A developmental dissociation in reinstatement of an extinguished fear response in rats. Neurobiol Learn Mem (2007) 88:48-57. doi:10.1016/j.nlm.2007.03.004

46. Gogolla N, Caroni P, Lüthi A, Herry C. Perineuronal nets protect fear memories from erasure. $\mathrm{Sci}$ ence (2009) 325:1258-61. doi:10. $1126 /$ science. 1174146

47. Langton JM, Kim JH, Nicholas J Richardson R. The effect of the NMDA receptor antagonist MK801 on the acquisition and extinction of learned fear in the developing rat. Learn Mem (2007) 14:6658. doi: $10.1101 / \mathrm{lm} .692407$

48. Ji J, Maren S. Hippocampal involvement in contextual modulation of fear extinction. Hippocampus (2007) 17:749-58. doi: 10.1002/hipo.20331

49. Myers KM, Davis M. Mechanisms of fear extinction. Mol Psychiatry (2007) 12:120-50. doi:10.1038/sj. mp.4001939

50. Quirk GJ, Mueller D. Neural mechanisms of extinction learning and retrieval. Neuropsychopharmacology (2007) 33:56-72. doi:10.1038/ sj.npp.1301555

51. Goosens KA, Maren S. NMDA receptors are essential for the acquisition, but not expression, of conditional fear and associative spike firing in the lateral amygdala. Eur J Neurosci (2004) 20:53748. doi:10.1111/j.1460-9568.2004. 03513.x

52. Corcoran KA, Maren S. Hippocampal inactivation disrupts contextual retrieval of fear memory after extinction. J Neurosci (2001) 21:1720-6

53. Corcoran KA, Quirk GJ. Activity in prelimbic cortex is necessary for the expression of learned, but not innate, fears. $J \mathrm{Neu}$ rosci (2007) 27:840-4. doi:10. 1523/JNEUROSCI.5327-06.2007

54. Quirk GJ, Beer JS. Prefrontal involvement in the regulation of emotion: convergence of rat and human studies. Curr Opin Neurobiol (2006) 16:723-7. doi:10.1016/ j.conb.2006.07.004

55. Phelps EA, Delgado MR, Nearing KI, LeDoux JE. Extinction learning in humans: role of the amygdala and vmPFC. Neuron (2004) 43:897-905. doi:10.1016/j.neuron. 2004.08.042

56. Kalisch R, Korenfeld E, Stephan KE, Weiskopf N, Seymour B, Dolan RJ. Context-dependent human extinction memory is mediated by a ventromedial prefrontal and hippocampal network. J Neurosci (2006) 26:9503-11.
doi:10.1523/JNEUROSCI.202106.2006

57. Bremner JD, Vermetten E, Schmahl C, Vaccarino V, Vythilingam $\mathrm{M}$, Afzal $\mathrm{N}$, et al. Positron emission tomographic imaging of neural correlates of a fear acquisition and extinction paradigm in women with childhood sexual-abuse-related post-traumatic stress disorder. Psychol Med (2005) 35:791-806. doi:10.1017/S0033291704003290

58. Kim JH, Richardson R. The effect of temporary amygdala inactivation on extinction and reextinction of fear in the developing rat: unlearning as a potential mechanism for extinction early in development. $J$ Neurosci (2008) 28:1282-90. doi:10.1523/ JNEUROSCI.4736-07.2008

59. Kim JH, Hamlin AS, Richardson R. Fear extinction across development: the involvement of the medial prefrontal cortex as assessed by temporary inactivation and immunohistochemistry. J Neurosci (2009) 29:108028. doi:10.1523/JNEUROSCI.059609.2009

60. MacDonald S, Uesiliana K, Hayne $\mathrm{H}$. Cross-cultural and gender differences in childhood amnesia. Memory (2000) 8:365-76. doi:10. $1080 / 09658210050156822$

61. Hayne H, MacDonald S, Barr R. Developmental changes in the specificity of memory over the second year of life. Infant Behav Dev (1997) 20:233-45. doi:10. 1016/S0163-6383(97)90025-4

62. Hayne H, Boniface J, Barr R. The development of declarative memory in human infants: age-related changes in deferred imitation. Behav Neurosci (2000) 114: 77-83. doi:10.1037/0735-7044. 114.1.77

63. Rovee-Collier C, Cuevas K. The development of infant memory. In: Courage M, Cowan N, editors. The Development of Memory in Infancy and Childhood. Hoboken: Psychology Press (2009). p. 11-41.

64. Bronstein PM, Hirsch SM. Ontogeny of defensive reactions in Norway rats. J Comp Physiol Psychol (1976) 90:620-9. doi:10.1037/h0077224

65. Takahashi LK. Ontogeny of behavioral inhibition induced by unfamiliar adult male conspecifics in preweanling rats. Physiol Behav (1992) 52:493-8. doi:10.1016/ 0031-9384(92)90336-Z

66. Wiedenmayer CP, Barr GA. Developmental changes in c-fos 
expression to an age-specific social stressor in infant rats. Behav Brain Res (2001) 126:147-57. doi:10. 1016/S0166-4328(01)00260-1

67. Takahashi LK, Rubin WW. Corticosteroid induction of threatinduced behavioral inhibition in preweanling rats. Behav Neurosci (1993) 107:860-6. doi:10.1037/ 0735-7044.107.5.860

68. Takahashi LK. Organizing action of corticosterone on the development of behavioral inhibition in the preweanling rat. Brain Res Dev Brain Res (1994) 81:121-7. doi:10. 1016/0165-3806(94)90074-4

69. Moriceau S, Roth TL, Okotoghaide T, Sullivan RM. Corticosterone controls the developmental emergence of fear and amygdala function to predator odors in infant rat pups. Int J Dev Neurosci (2004) 22:415-22. doi:10.1016/j.ijdevneu. 2004.05.011

70. Camp LL, Rudy JW. Changes in the categorization of appetitive and aversive events during postnatal development of the rat. Dev Psychobiol (1988) 21:25-42. doi:10. 1002/dev.420210103

71. Upton KJ, Sullivan RM. Defining age limits of the sensitive period for attachment learning in rat pups. Dev Psychobiol (2010) 52:453-64. doi:10.1002/dev.20448

72. Raineki C, Moriceau S, Sullivan RM. Developing a neurobehavioral animal model of infant attachment to an abusive caregiver. Biol Psychiatry (2010) 67:1137-45. doi:10.1016/j. biopsych.2009.12.019

73. Moriceau S, Sullivan RM. Corticosterone influences on mammalian neonatal sensitiveperiod learning. Behav Neurosci (2004) 118:274-81. doi:10.1037/0735-7044.118.2.274

74. Moriceau S, Wilson DA, Levine S, Sullivan RM. Dual circuitry for odor-shock conditioning during infancy: corticosterone switches between fear and attraction via amygdala. J Neurosci (2006) 26:6737-48. doi:10.1523/ JNEUROSCI.0499-06.2006

75. Moriceau S, Shionoya K, Jakubs K, Sullivan RM. Early-life stress disrupts attachment learning: the role of amygdala corticosterone, locus ceruleus corticotropin releasing hormone, and olfactory bulb norepinephrine. J Neurosci (2009) 29:15745-55. doi:10.1523/ JNEUROSCI.4106-09.2009

76. Callaghan B, Richardson R. The effect of adverse rearing environments on persistent memories in young rats: removing the brakes on infant fear memories. Transl Psychiatry (2012) 2:e138. doi:10. 1038/tp.2012.65

77. Callaghan BL, Richardson R. Maternal separation results in early emergence of adult-like fear and extinction learning in infant rats. Behav Neurosci (2011) 125:20-8. doi:10.1037/a0022008

78. Graham B, Richardson R. Memory of fearful events: the role of fibroblast growth factor-2 in fear acquisition and extinction. Neuroscience (2011) 189:156-69. doi:10.1016/j. neuroscience.2011.05.041

79. Turner CA, Watson SJ, Akil H. The fibroblast growth factor family: neuromodulation of affective behavior. Neuron (2012) 76:16074. doi:10.1016/j.neuron.2012.08. 037

80. Cheng Y, Tao Y, Black IB, DiCiccoBloom E. A single peripheral injection of basic fibroblast growth factor (bFGF) stimulates granule cell production and increases cerebellar growth in newborn rats. J Neurobiol (2001) 46:220-9. doi:10.1002/10974695(20010215)46:3<220::AIDNEU1004>3.0.CO;2-P

81. Ohkubo Y, Uchida AO, Shin D, Partanen J, Vaccarino FM. Fibroblast growth factor receptor 1 is required for the proliferation of hippocampal progenitor cells and for hippocampal growth in mouse. $\mathrm{JNeu}$ rosci (2004) 24:6057-69. doi:10. 1523/JNEUROSCI.1140-04.2004

82. Graham BM, Richardson R. Early-life exposure to fibroblast growth factor-2 facilitates context-dependent long-term memory in developing rats. Behav Neurosci (2010) 124:337. doi:10.1037/a0019582

83. Rudy JW, Morledge, P. Ontogeny of contextual fear conditioning in rats: implications for consolidation, infantile amnesia, and hippocampal system function. Behav Neurosci (1994) 108: 227-34. doi:10.1037/0735-7044. 108.2.227

84. Molteni R, Fumagalli F, Magnaghi V, Roceri $M$, Gennarelli M, Racagni G, et al. Modulation of fibroblast growth factor2 by stress and corticosteroids: from developmental events to adult brain plasticity. Brain Res Rev (2001) 37:249-58. doi:10. 1016/S0165-0173(01)00128-X

85. Anderson KJ, Dam D, Lee S, Cotman CW. Basic fibroblast growth factor prevents death of lesioned cholinergic neurons in vivo. Nature (1988) 332:360-1. doi: $10.1038 / 332360 \mathrm{a} 0$

86. Gomez-Pinilla F, Vu L, Cotman CW. Regulation of astrocyte proliferation by FGF-2 and heparan sulfate in vivo. J Neurosci (1995) 15:2021-9.

87. Bland ST, Schmid MJ, Greenwood BN, Watkins LR, Maier SF. Behavioral control of the stressor modulates stress-induced changes in neurogenesis and fibroblast growth factor-2. Neuroreport (2006) 17:593-7. doi:10.1097/ 00001756-200604240-00008

88. Bland ST, Tamlyn JP, Barrientos RM, Greenwood BN, Watkins LR, Campeau S, et al. Expression of fibroblast growth factor-2 and brain-derived neurotrophic factor mRNA in the medial prefrontal cortex and hippocampus after uncontrollable or controllable stress. Neuroscience (2007) 144:1219-28. doi:10.1016/j. neuroscience.2006.11.026

89. Turner CA, Calvo N, Frost DO, Akil H, Watson SJ. The fibroblast growth factor system is downregulated following social defeat. Neurosci Lett (2008) 430 : 147-50. doi:10.1016/j.neulet.2007. 10.041

90. Fagiolini M, Hensch TK Inhibitory threshold for criticalperiod activation in primary visual cortex. Nature (2000) 404:183-6. doi:10.1038/35004582

91. Hensch TK. Critical period mechanisms in developing visual cortex. Curr Top Dev Biol (2005) 69:215-37. doi:10.1016/S00702153(05)69008-4

92. Levelt CN, Hübener M. Criticalperiod plasticity in the visual cortex. Neuroscience (2012) 35:30930.

93. Gogolla N, LeBlanc JJ, Quast KB, Südhof TC, Fagiolini M, Hensch TK. Common circuit defect of excitatory-inhibitory balance in mouse models of autism. J Neurodev Disord (2009) 1: 172-81. doi:10.1007/s11689-0099023-X

94. LeBlanc JJ, Fagiolini M. Autism: a "critical period" disorder? Neural Plast (2011) 2011:921680. doi:10. 1155/2011/921680

95. Lupien SJ, McEwen BS, Gunnar MR, Heim C. Effects of stress throughout the lifespan on the brain, behaviour and cognition. Nat Rev Neurosci (2009) 10:43445. doi:10.1038/nrn2639

96. Banks MS, Aslin RN, Letson RD. Sensitive period for the development of human binocular vision.
Science (1975) 190:675-7. doi:10. 1126/science. 1188363

97. Harrison RV, Gordon KA, Mount RJ. Is there a critical period for cochlear implantation in congenitally deaf children? Analyses of hearing and speech perception performance after implantation. Dev Psychobiol (2005) 46:252-61. doi:10.1002/dev.20052

98. Johnson JS, Newport EL. Critical period effects on universal properties of language: the status of subjacency in the acquisition of a second language. Cognition (1991) 39:215-58. doi:10. 1016/0010-0277(91)90054-8

99. Birdsong D, Molis M. On the evidence for maturational constraints in second-language acquisition. $J$ Mem Lang (2001) 44:235-49. doi: 10.1006/jmla.2000.2750

100. Bos K, Zeanah CH, Fox NA, Drury SS, McLaughlin KA, Nelson CA. Psychiatric outcomes in young children with a history of institutionalization. Harv Rev Psychiatry (2011) 19:15-24. doi:10.3109/ 10673229.2011.549773

101. Fox K. A critical period for experience-dependent synaptic plasticity in rat barrel cortex. $J$ Neurosci (1992) 12:1826-38.

102. Nelson DA, Marler P, Palleroni A. A comparative approach to vocal learning: intraspecific variation in the learning process. Anim Behav (1995) 50:83-97. doi:10. 1006/anbe.1995.0223

103. Doupe AJ, Kuhl PK. Birdsong and human speech: common themes and mechanisms. Annu Rev Neurosci (1999) 22:567-631. doi:10. 1146/annurev.neuro.22.1.567

104. Balmer TS, Carels VM, Frisch JL, Nick TA. Modulation of perineuronal nets and parvalbumin with developmental song learning. J Neurosci (2009) 29:12878-85. doi:10.1523/JNEUROSCI.297409.2009

105. Nowicka D, Soulsby S, SkangielKramska J, Glazewski S. Parvalbumin-containing neurons, perineuronal nets and experience-dependent plasticity in murine barrel cortex. Eur J Neurosci (2009) 30:2053-63. doi:10. 1111/j.1460-9568.2009.06996.x

106. Hubel DH, Wiesel TN. Receptive fields, binocular interaction and functional architecture in the cat's visual cortex. J Physiol (1962) 160:106-54.

107. Wiesel TN, Hubel DH. Single-cell responses in striate cortex of kittens deprived of vision in one eye. J Neurophysiol (1963) 26:1013-7. 
108. Hensch TK. Critical period plasticity in local cortical circuits. Nat Rev Neurosci (2005) 6:877-88. doi:10. 1038/nrn1787

109. Hensch TK, Fagiolini M, Mataga N, Stryker MP, Baekkeskov S, Kash SF. Local GABA circuit control of experience-dependent plasticity in developing visual cortex. Science (1998) 282:1504-8. doi:10.1126/ science.282.5393.1504

110. Hanover JL, Huang ZJ, Tonegawa S, Stryker MP. Brain-derived neurotrophic factor overexpression induces precocious critical period in mouse visual cortex. $J$ Neurosci (1999) 19:RC40.

111. Huang ZJ, Kirkwood A, Pizzorusso T, Porciatti V, Morales B, Bear MF, et al. BDNF regulates the maturation of inhibition and the critical period of plasticity in mouse visual cortex. Cell (1999) 98:739-55. doi: 10.1016/S0092-8674(00)81509-3

112. Pizzorusso T, Medini P, Berardi N, Chierzi S, Fawcett JW, Maffei L. Reactivation of ocular dominance plasticity in the adult visual cortex. Science (2002) 298:1248-51. doi:10.1126/science.1072699

113. McGee AW, Yang Y, Fischer QS, Daw NW, Strittmatter SM. Experience-driven plasticity of visual cortex limited by myelin and Nogo receptor. Science (2005) 309:2222-6. doi:10.1126/science. 1114362

114. Chklovskii DB, Mel B, Svoboda K. Cortical rewiring and information storage. Nature (2004) 431:782-8. doi:10.1038/nature03012

115. GrandPré T, Li S, Strittmatter SM. Nogo-66 receptor antagonist peptide promotes axonal regeneration. Nature (2002) 417:547-51. doi:10. $1038 / 417547 \mathrm{a}$

116. Pham TA, Impey S, Storm DR, Stryker MP. CRE-mediated gene transcription in neocortical neuronal plasticity during the developmental critical period. $\mathrm{Neu}$ ron (1999) 22:63-72. doi:10.1016/ S0896-6273(00)80679-0

117. Pham TA, Graham SJ, Suzuki S, Barco A, Kandel ER, Gordon B, et al. A semi-persistent adult ocular dominance plasticity in visual cortex is stabilized by activated CREB. Learn Mem (2004) 11:738-47. doi: 10.1101/lm.75304

118. Beaver CJ, Ji Q, Fischer QS, Daw NW. Cyclic AMP-dependent protein kinase mediates ocular dominance shifts in cat visual cortex. Nat Neurosci (2001) 4:159-63. doi: $10.1038 / 83985$

119. Vo N, Klein ME, Varlamova $\mathrm{O}$, Keller DM, Yamamoto $\mathrm{T}$,
Goodman RH, et al. A cAMPresponse element binding proteininduced microRNA regulates neuronal morphogenesis. Proc Natl Acad Sci U S A (2005) 102:1642631. doi:10.1073/pnas.0508448102

120. Tognini P, Putignano E, Coatti A, Pizzorusso T. Experiencedependent expression of miR-132 regulates ocular dominance plasticity. Nat Neurosci (2011) 14:1237-9. doi:10.1038/nn.2920

121. Galanopoulou AS. Dissociated gender-specific effects of recurrent seizures on GABA signaling in CA1 pyramidal neurons: role of GABAA receptors. J Neurosci (2008) 28:1557-67. doi:10.1523/ JNEUROSCI.5180-07.2008

122. Roceri M, Cirulli F, Pessina C, Peretto P, Racagni G, Riva MA Postnatal repeated maternal deprivation produces age-dependent changes of brain-derived neurotrophic factor expression in selected rat brain regions. Biol Psychiatry (2004) 55:708-14. doi:10. 1016/j.biopsych.2003.12.011

123. Kikusui T, Kiyokawa Y, Mori Y. Deprivation of mother-pup interaction by early weaning alters myelin formation in male, but not female, ICR mice. Brain Res (2007) 1133:115-22. doi:10.1016/ j.brainres.2006.11.031

124. Ono M, Kikusui T, Sasaki N, Ichikawa M, Mori Y, MurakamiMurofushi K. Early weaning induces anxiety and precocious myelination in the anterior part of the basolateral amygdala of male Balb/c mice. Neuroscience (2008) 156:1103-10. doi:10.1016/ j.neuroscience.2008.07.078

125. Chan JR, Phillips LJ, Glaser M. Glucocorticoids and progestins signal the initiation and enhance the rate of myelin formation. Proc Natl Acad Sci U S A (1998) 95:10459-64. doi:10.1073/ pnas.95.18.10459

126. Bansal R, Miyake H, Nakamura I, Eto H, Gotoh A, Fujisawa M, et al. Fibroblast growth factors and their receptors in oligodendrocyte development: implications for demyelination and remyelination. Dev Neurosci (2002) 24:3546. doi:10.1159/000064944

127. Furusho M, Dupree JL, Nave K-A, Bansal R. Fibroblast growth factor receptor signaling in oligodendrocytes regulates myelin sheath thickness. $J$ Neurosci (2012) 32:6631-41. doi:10.1523/ JNEUROSCI.6005-11.2012

128. Sung JY, Shin SW, Ahn YS, Chung KC. Basic fibroblast growth factor-induced activation of novel CREB kinase during the differentiation of immortalized hippocampal cells. J Biol Chem (2001) 276 : 13858-66.

129. Peltier J, O’Neill A, Schaffer DV. PI3K/Akt and CREB regulate adult neural hippocampal progenitor proliferation and differentiation. Dev Neurobiol (2007) 67:1348-61. doi:10.1002/dneu. 20506

130. Uchida S, Hara K, Kobayashi A, Funato H, Hobara T, Otsuki $\mathrm{K}$, et al. Early life stress enhances behavioral vulnerability to stress through the activation of REST4-mediated gene transcription in the medial prefrontal cortex of rodents. I Neurosci (2010) 30:15007-18. doi:10.1523/ JNEUROSCI.1436-10.2010

131. Numakawa T, Yamamoto $\mathrm{N}$, Chiba S, Richards M, Ooshima Y, Kishi S, et al. Growth factors stimulate expression of neuronal and glial miR-132. Neurosci Lett (2011) 505:242-7. doi:10.1016/j.neulet.2011.10.025

132. Yehuda R, Engel SM, Brand SR, Seckl J, Marcus SM, Berkowitz GS. Transgenerational effects of posttraumatic stress disorder in babies of mothers exposed to the World Trade Center attacks during pregnancy. J Clin Endocrinol Metab (2005) 90:4115-8. doi:10.1210/jc. 2005-0550

133. Stein MB, Chartier MJ, Lizak MV, Jang KL. Familial aggregation of anxiety-related quantitative traits in generalized social phobia: clues to understanding "disorder" heritability? Am J Med Genet (2001) 105:79-83. doi:10.1002/ 1096-8628(20010108)105:1<79: :AID-AJMG1067>3.3.CO;2-6

134. Stein MB, Jang KL, Livesley W. Heritability of social anxietyrelated concerns and personality characteristics: a twin study. $J$ Nerv Ment Dis (2002) 190:219$24 . \quad$ doi:10.1097/00005053200204000-00002

135. Distel MA, Vink JM, Willemsen G, Middeldorp CM, Merckelbach HLGJ, Boomsma DI. Heritability of self-reported phobic fear. Behav Genet (2008) 38:24-33. doi: 10.1007/s10519-007-9182-z

136. Kim HK, Capaldi DM, Pears KC, Kerr DCR, Owen LD. Intergenerational transmission of internalising and externalising behaviours across three generations: genderspecific pathways. Crim Behav Ment Health (2009) 19:125-41. doi:10.1002/cbm.708
137. Roth TL, Lubin FD, Funk AJ, Sweatt JD. Lasting epigenetic influence of early-life adversity on the BDNF gene. Biol Psychiatry (2009) 65:760-9. doi:10.1016/j.biopsych. 2008.11.028

138. Franklin TB, Russig H, Weiss IC, Gräff J, Linder N, Michalon A, et al. Epigenetic transmission of the impact of early stress across generations. Biol Psychiatry (2010) 68:408-15. doi:10.1016/ j.biopsych.2010.05.036

139. Dietz DM, LaPlant Q, Watts EL, Hodes GE, Russo SJ, Feng J, et al. Paternal transmission of stressinduced pathologies. Biol Psychiatry (2011) 70:408-14. doi:10.1016/ j.biopsych.2011.05.005

140. Weiss IC, Franklin TB, Vizi S, Mansuy IM. Inheritable effect of unpredictable maternal separation on behavioral responses in mice. Front Behav Neurosci (2011) 5:3. doi:10. 3389/fnbeh.2011.00003

141. Champagne FA. Epigenetic mechanisms and the transgenerational effects of maternal care. Front Neuroendocrinol (2008) 29:386-97. doi:10.1016/j.yfrne.2008.03.003

142. Curley JP, Mashoodh R. Parentof-origin and trans-generational germline influences on behavioral development: the interacting roles of mothers, fathers, and grandparents. Dev Psychobiol (2010) 52:312-30. doi:10.1002/dev.20430

143. Rajasethupathy P, Fiumara F, Sheridan R, Betel D, Puthanveettil SV, Russo JJ, et al. Characterization of small RNAs in aplysia reveals a role for miR-124 in constraining synaptic plasticity through CREB. Neuron (2009) 63:803-17. doi:10. 1016/j.neuron.2009.05.029

144. Grandjean V, Gounon P, Wagner N, Martin L, Wagner KD, Bernex F, et al. The miR-124-Sox9 paramutation: RNA-mediated epigenetic control of embryonic and adult growth. Development (2009) 136:3647-55. doi:10.1242/ dev.041061

145. Kessler RC, McLaughlin KA, Green JG, Gruber MJ, Sampson NA, Zaslavsky AM, et al. Childhood adversities and adult psychopathology in the WHO World Mental Health Surveys. Br J Psychiatry (2010) 197:378-85. doi:10. 1192/bjp.bp.110.080499

146. Glaser J-P, van Os J, Portegijs P, Myin-Germeys I. Childhood trauma and emotional reactivity to daily life stress in adult frequent attenders of general practitioners. $J$ Psychosom Res (2006) 61:229. doi: 10.1016/j.jpsychores.2006.04.014 
147. McLaughlin KA, Green JG, Gruber MJ, Sampson NA, Zaslavsky AM, Kessler RC. Childhood adversities and adult psychiatric disorders in the national comorbidity survey replication II: associations with persistence of DSMIV disorders. Arch Gen Psychiatry (2010) 67:124-32. doi:10.1001/ archgenpsychiatry.2009.187

148. Binder EB, Bradley RG, Liu W, Epstein MP, Deveau TC, Mercer $\mathrm{KB}$, et al. Association of FKBP5 polymorphisms and childhood abuse with risk of posttraumatic stress disorder symptoms in adults. JAMA (2008) 299:1291-305. doi: 10.1001/jama.299.11.1291

149. Bradley RG, Binder EB, Epstein MP, Tang Y, Nair HP, Liu W, et al. Influence of child abuse on adult depression: moderation by the corticotropin-releasing hormone receptor gene. Arch Gen Psychiatry (2008) 65:190. doi:10. 1001/archgenpsychiatry.2007.26

150. Graham BM, Richardson R. Acute systemic fibroblast growth factor2 enhances long-term extinction of fear and reduces reinstatement in rats. Neuropsychopharmacology (2009) 34:1875-82. doi:10.1038/ npp. 2009.14

151. Graham BM, Richardson R. Fibroblast growth factor2 enhances extinction and reduces renewal of conditioned fear. Neuropsychopharmacology (2010) 35:1348-55. doi:10.1038/npp.2010.3

152. Graham BM, Richardson R. Fibroblast growth factor-2 alters the nature of extinction. Learn Mem (2011) 18:80-4. doi:10.1101/lm.2006511

153. Graham BM, Richardson R. Intraamygdala infusion of fibroblast growth factor 2 enhances extinction and reduces renewal and reinstatement in adult rats.
J Neurosci (2011) 31:14151-7. doi:10.1523/JNEUROSCI.301411.2011

154. Langton JM, Richardson R. Dcycloserine facilitates extinction the first time but not the second time: an examination of the role of NMDA across the course of repeated extinction sessions. Neuropsychopharmacology (2008) 33:3096-102. doi:10.1038/npp

155. Laurent V, Marchand AR, Westbrook RF. The basolateral amygdala is necessary for learning but not relearning extinction of context conditioned fear. Learn Mem (2008) 15:304-14. doi:10.1101/lm. 1080108

156. Chan WYM, McNally GP. Conditioned stimulus familiarity determines effects of MK-801 on fear extinction. Behav Neurosci (2009) 123:303. doi:10.1037/ a0014988

157. Langton JM, Richardson R. The temporal specificity of the switch from NMDAr-dependent extinction to NMDAr-independent reextinction. Behav Brain Res (2010) 208:646-9. doi:10.1016/j.bbr.2009. 12.018

158. Kim JH, Richardson R. Extinction in preweanling rats does not involve NMDA receptors. Neurobiol Learn Mem (2010) 94:176-82. doi:10.1016/j.nlm.2010.05.004

159. Karpova NN, Pickenhagen A, Lindholm J, Tiraboschi E, Kulesskaya N, Ágústsdóttir A, et al. Fear erasure in mice requires synergy between antidepressant drugs and extinction training. Science (2011) 334:1731-4. doi:10.1126/science.1214592

160. Pampallona S, Bollini P, Tibaldi G, Kupelnick B, Munizza C. Combined pharmacotherapy and psychological treatment for depression: a systematic review. Arch Gen Psychiatry (2004)
61:714. doi:10.1001/archpsyc.61. 7.714

161. Fergusson DM, Horwood L, Lynskey MT. Childhood sexual abuse and psychiatric disorder in young adulthood: II. Psychiatric outcomes of childhood sexual abuse. J Am Acad Child Adolesc Psychiatry (1996) 35: 1365-74. doi:10.1097/00004583199610000-00023

162. Nikulina V, Widom CS, Czaja S The role of childhood neglect and childhood poverty in predicting mental health, academic achievement and crime in adulthood. Am J Community Psychol (2011) 48:309-21. doi:10.1007/ s10464-010-9385-y

163. Milad MR, Rauch SL, Pitman RK, Quirk GJ. Fear extinction in rats: implications for human brain imaging and anxiety disorders. Biol Psychol (2006) 73: 61-71. doi:10.1016/j.biopsycho. 2006.01.008

164. Milad MR, Quirk GJ. Fear extinction as a model for translational neuroscience: ten years of progress. Annu Rev Psychol (2012) 63:129-51. doi:10.1146/annurev. psych.121208.131631

165. Jacobs WJ, Nadel L. Stress-induced recovery of fears and phobias. Psychol Rev (1985) 92:512-31. doi:10. 1037/0033-295X.92.4.512

166. Jacobs WJ, Nadel L. The first panic attack: a neurobiological theory. Can J Exp Psychol (1999) 53:92107. doi: $10.1037 / \mathrm{h} 0087302$

167. Mineka S, Zinbarg R. A contemporary learning theory perspective on the etiology of anxiety disorders: it's not what you thought it was. Am Psychol (2006) 61: 10-26. doi:10.1037/0003-066X.61. 1.10

168. Mineka S, Oehlberg K. The relevance of recent developments in classical conditioning to understanding the etiology and maintenance of anxiety disorders. Acta Psychol (Amst) (2008) 127:567-80. doi:10.1016/j.actpsy.2007.11.007

169. Zorawski M, Cook CA, Kuhn CM, LaBar KS. Sex, stress, and fear: individual differences in conditioned learning. Cogn Affect Behav Neurosci (2005) 5:191-201. doi:10. 3758/CABN.5.2.191

170. Guthrie RM, Bryant RA. Extinction learning before trauma and subsequent posttraumatic stress. Psychosom Med (2006) 68:307-11. doi:10.1097/01.psy.0000208629. 67653.cc

Conflict of Interest Statement: The authors declare that the research was conducted in the absence of any commercial or financial relationships that could be construed as a potential conflict of interest.

Received: 03 May 2013; accepted: 31 July 2013; published online: 13 August 2013. Citation: Callaghan BL, Graham BM, Li $S$ and Richardson $R$ (2013) From resilience to vulnerability: mechanistic insights into the effects of stress on transitions in critical period plasticity. Front. Psychiatry 4:90. doi: 10.3389/fpsyt.2013.00090

This article was submitted to Frontiers in Molecular Psychiatry, a specialty of Frontiers in Psychiatry.

Copyright (c) 2013 Callaghan, Graham, Li and Richardson. This is an open-access article distributed under the terms of the Creative Commons Attribution License (CC BY). The use, distribution or reproduction in other forums is permitted, provided the original author(s) or licensor are credited and that the original publication in this journal is cited, in accordance with accepted academic practice. No use, distribution or reproduction is permitted which does not comply with these terms. 